\title{
UMA ABORDAGEM COMPREENSIVA DA DIGNIDADE HUMANA
}

\author{
Fabrício José Rodrigues de Lemos ${ }^{1}$ \\ Vicente de Paulo Barretto ${ }^{2}$
}

\section{Resumo}

A dignidade é um conceito que pode abarcar inúmeras interpretações - o termo se expandiu de uma qualidade afeta a apenas alguns poucos indivíduos, em razão de seu status, para uma qualidade universal, irrevogável, inalienável. Portanto, utilizando-se do método de pesquisa bibliográfico, com base na doutrina do professor de Harvard Michael Rosen, cuja obra, claramente inspirada pela ética kantiana, visa apresentar uma faceta nova para a resolução de velhos problemas, o artigo busca demonstrar, de forma compreensiva, como o paradigma de dignidade se desenvolveu na história e como, ainda hoje, há dificuldades em expressá-lo de forma clara. O livro procura subsidiar uma discussão mais aprofundada sobre o tema e sobre a maneira com a qual se lida os problemas contemporâneos dos Direitos Humanos e da Bioética. Considerando a humanidade constante em cada indivíduo, a contribuição de Rosen reside em analisar qual a melhor maneira de lidar com seres nãoautônomos, um dos grandes desafios da filosofia e da ciência contemporânea.

Palavras-chave: Dignidade. Autonomia. Liberdade. Immanuel Kant. Michael Rosen.

\section{INTRODUÇÃO}

A dignidade encontra-se em um panteão de conceitos facilmente identificáveis e amplamente difundidos, porém, de difícil conceituação - encontram-se, por exemplo, no mesmo âmbito, os conceitos de liberdade, amor, paz. Por isso, ainda que dignidade não possa ser claramente conceituada, o presente artigo possui o foco de, pelo menos, aclarar a discussão sobre o tema e fornecer subsídios para que se possam discutir algumas questões relativas aos Direitos Humanos e à Bioética com base no fundamento kantiano de que as pessoas, em razão de sua autonomia e da dignidade que dela corresponde, devem ser tratadas como fim e nunca como meios.

\footnotetext{
${ }^{1}$ Mestrando em Direito Público, na Linha de Pesquisa Sociedade, Novos Direitos e Transnacionalização, pela Universidade do Vale do Rio dos Sinos - Unisinos (2014). Integrante do Núcleo de Direitos Humanos da Unisinos (NDH). E-mail: fabrjr@gmail.com

2 Pós-doutor pela Maison des Sciences de L'Homme, Paris. Professor do Programa de Pós-Graduação em Direito da UNESA; professor do Programa de Pós-Graduação em Direito da UNISINOS; Decano da Escola de Direito da UNISINOS. Professor visitante da Faculdade de Direito da Universidade de Coimbra. Coordenador-científico do Dicionário de Filosofia do Direito e do Dicionário de Filosofia Política. Consultor ad hoc da área de Direito e de Filosofia da CAPES; consultor ad hoc da área de Direito do CNPQ. Bolsista de produtividade científica do CNPQ - nível 1. Membro do Board of Governors da International Association of Law Schools (IALS).E-mail: vpbarreto@terra.com.br
} 
Nesse passo, o artigo, tomando como referência a excelente obra do doutrinador Michael Rosen sobre as diferentes concepções de dignidade e acerca de problemas éticos relativos à questão da dignidade e do tratamento aos outros e à vida em sociedade, visa, de início, uma vez delimitados os diversos escopos dados ao tema da dignidade, trazer foco às questões e aos problemas postos pelo autor, de maneira a demonstrar, desse modo, como o tratamento com respeito pode ser uma forma de obtenção do reino dos fins kantiano.

Também, para tanto, buscou junto à doutrina, tanto nacional quanto internacional, algumas das mais importantes contribuições ao tema, contudo, seguindo a linha de pensamento de Rosen, focando-se, primordialmente, na obra de Immanuel Kant e daqueles influenciados pelo filósofo alemão.

Então, o artigo possui como objetivo a instigação de reflexões, através de uma análise filosófico-histórica mais aprofundada do conceito, em relação à importante necessidade da delimitação da dignidade: o faz, de maneira a proporcionar subsídios para que, consoante os padrões kantianos, possa ocorrer uma maior facilidade para a vida em sociedade e maior embasamento filosófico na resposta de problemas prementes do mundo contemporâneo.

Ao final, buscará apresentar diferentes visões acerca do conceito, culminando em uma abordagem que, seguindo o paradigma kantiano, possa, de maneira satisfatória, responder às indagações oriundas de problemas da teoria de Direitos Humanos e Bioética.

\section{REFLEXÕES FILOSÓFICAS E HISTÓRICAS SOBRE DIGNIDADE}

Ao tratar de dignidade, impossível se desvencilhar da noção criada por Immanuel Kant: o influente filósofo alemão viveu de 1724 a 1804, tendo escrito diversas obras. Destas, há uma tríade de livros que se destacam: Crítica da Razão Pura, Crítica da Razão Prática e Fundamentação da Metafísica dos Costumes. A importância do autor se dá muito em razão do desempenho de seu papel histórico, ao introduzir no pensamento filosófico de sua época a ideia de que todos os seres humanos possuem valor incondicional e intrínseco, a partir de sua famosa afirmação de que seres humanos devem ser sempre tratados como fins, nunca como meios. (ROSEN, 2012, p. 10).

Em sua primeira Crítica, Kant buscou trazer racionalidade à ideia de Deus e da imortalidade da alma, princípios basilares da religião cristã: estabeleceu, nas palavras de Chagas (2009, p. 27), um conceito teológicomoral que acabou por resultar em um percalço no conjunto de sua obra posterior. Explica-se: a lei moral, por um lado, condiciona a vontade do homem, ceifando parte de sua liberdade por ser mandamento necessário da razão prática pura; por outro lado, soma-se à concepção moral o conceito de felicidade - da dignidade moral como pressuposto no alcance da felicidade -, resultando na obrigatoriedade do cumprimento da lei ou dever moral, pressupondo-se, desse modo, a ideia de Deus e da imortalidade da alma humana: o resultado dessa decorrência 
lógica é a heteronomia da vontade do homem, que limita, por sua vez, ainda mais, a sua liberdade, o seu livrearbítrio.

Na Crítica da Razão Prática (2003), Kant busca, em suma, encontrar e disseminar um princípio moral universalmente válido, capaz de produzir um ordenamento moral que possa ser estendido à totalidade da sociedade. A razão prática, no pensamento kantiano, caracteriza-se como um regramento prático que nos dita o ordenamento moral que devemos seguir de maneira a nos tornarmos dignos de sermos felizes, ainda que tal virtude não possa garantir certeza em relação ao resultado almejado (CORTES, 2010, p. 74): portanto, a felicidade, na qualidade de dignidade de ser feliz, é o possível resultado da vida do homem que agiu de modo moral. (CHAGAS, 2009, p. 26).

O objetivo, a finalidade da razão prática, entretanto, não é o de prover subsídios à felicidade do homem que agiu moralmente, mas sim o de promover o sumo bem (CORTES, 2010), eis que, em um mundo perfeito, aquele no qual todos agem de forma moral, o bem é praticado sem que as pessoas vejam umas nas outras um meio, mas somente um fim em si mesmas.

Por isso, na Fundamentação da Metafísica dos Costumes, Kant (2007) lança a base para seu princípio da dignidade humana. Ali, especificou a ideia do imperativo categórico: age apenas segundo uma máxima tal que possas ao mesmo tempo querer que ela se torne lei universal. (KANT, 2007, p. 59). Por isso, a dignidade, na visão kantiana, tem por fundamento a autonomia ${ }^{3}$, a vontade - " [ ... ] seres humanos têm dignidade contanto tenham moralidade, qualquer que seja a realidade externa”. (ROSEN, 2012, p. 25, tradução nossa). ${ }^{4}$

Sobre a questão da liberdade inerente ao ser humano, Kant, considerando-o um fim em si mesmo, aduz que a dignidade somente existe com autonomia - sem ela, a ideia do próprio valor pessoal a nada se reduz - só há sentido para a lei moral caso esta esteja voltada para seres dotados de dignidade própria; sem essa ligação com a moralidade, a própria ideia de dignidade se esvai. (AGOSTINI, 2009, p. 88).

Em um mundo ideal no qual todos pautem a sua conduta pelo imperativo categórico, situação chamada por ele de reino dos fins (KANT, 2007, p. 75-76), , tudo tem ou um preço ou uma dignidade. As coisas que têm

\footnotetext{
3 "O conceito de autonomia aparece então para substantivar o agir moral. Kant define a autonomia: 'autonomia da vontade é aquela sua propriedade graças à qual ela é para si mesma a sua lei (independentemente da natureza dos objetos do querer). O princípio da autonomia é, portanto: não escolher senão de modo a que as máximas da escolha estejam incluídas simultaneamente no querer mesmo, como lei universal'. A manifestação da vontade expressa a dependência do agente moral à lei universal, vale dizer, à moralidade como condição de materialização das relações dos indivíduos em sociedade. A participação no reino dos fins pressupõe essa adequação à moralidade, que irá se concretizar através de vontades autônomas, que para serem autônomas necessitam da liberdade”. (BARRETTO, 2010, p. 76).

${ }^{4}[. .$.$] human beings have dignity so long as they have morality, whatever external reality may turn out to be like. (ROSEN, 2012, p.$ 25).

${ }^{5}$ Cumpre colacionar a passagem de Kant, conforme indicada por Barretto (2010, p. 73): "no reino dos fins [aquele que Kant se refere como sendo a ligação sistemática de vários seres racionais por meio de leis comuns] tudo tem ou um preço ou uma dignidade. Quando uma coisa tem um preço, pode-se pôr em vez dela qualquer outra como equivalente; mas quando uma coisa está acima de todo o preço, e, portanto, não permite equivalente, então ela tem dignidade... aquilo, porém, que constitui a condição vol.08, nº.03, Rio de Janeiro, 2015.pp. 1815-1826 1817
} 
preço podem ser substituídas por outras equivalentes. Mas quando uma coisa está acima de todo o preço, e não pode ser substituída por outra equivalente, ela tem dignidade. Tal é a situação singular da pessoa humana.

\begin{abstract}
A teoria moral kantiana tem sido irrefletidamente confundida com o projeto individualista moderno, sem que se perceba que, nas fórmulas morais kantianas, o outro - pela sua própria dignidade - é uma exigência a priori da própria autonomia. $\mathrm{O}$ outro se inscreve no dever que determina a ação moral, pois o imperativo categórico ao qual a máxima (princípio subjetivo) da ação deve se conformar refere-se a algo que tenha 'em si, um valor absoluto'. O ser que tem, em si, um valor absoluto é o homem, como sujeito da lei moral. Daí a necessidade de jamais ser considerado o homem como meio, mas como fim em si: 'age de tal maneira que a humanidade seja usada tanto na sua própria pessoa como na pessoa de qualquer outro, sempre e simultaneamente como fim, nunca simplesmente como meio'. Não porque o ser humano seja uma mônada autossuficiente, mas porque ele tem um valor igualmente partilhado por todos. (BARRETTO; BRAGATO, 2013, p. 255).
\end{abstract}

Kant fundamenta, assim, a dignidade na capacidade única do ser humano de agir moralmente - tal definição veio a ter influência decisiva na teoria de Direitos Humanos e, consequentemente, da Bioética, como se irá perceber: Kant sustenta que, em razão da singular capacidade humana de poder agir moralmente, o ser humano possui dignidade, valor. E é justamente por esse valor intrínseco e da necessidade do tratamento respeitoso que corresponde daí e da lei moral que as pessoas devem ser tratadas como fins, nunca como meios. Nesse sentido, Kant vincula respeito à lei moral nas ações e respeito pelas pessoas como um fim em nossas relações com eles em um nó inquebrável. (KATEB, 2011, p. 13).

Contudo, a capacidade de agir moralmente, além de legitimar a existência de dignidade pelo ser humano, também o responsabiliza por seus atos: por causa de sua imputação moral, o ser humano torna-se responsável por um ato bom ou mau; ao contrário da imputação jurídica, decorrente de infração de norma, a responsabilidade moral remete à constatação da livre subjetividade do agente - do seu poder de agir moralmente. (BARRETTO, 2013, p. 83).

Nesse sentido, justamente tendo como referencial teórico a obra de Immanuel Kant, o britânico Michael Rosen, eminente professor de filosofia política em Harvard, concebeu, após diversas palestras sobre o tema, ministradas na universidade britânica de Oxford, um livro denominado Dignity: its history and meaning (2012), no qual apresenta, em três capítulos, uma abordagem compreensiva da dignidade humana: trata acerca do significado de dignidade, sobre a legislação referente e, ao final, sobre o dever para com a humanidade.

Em suas primeiras palavras, Rosen (2012, p. 01) coloca-se em uma situação desconfortável: mencionando a crítica do filósofo alemão do século XIX Arthur Schopenhauer ${ }^{6}$ ao conceito de dignidade - que

só graças à qual qualquer coisa pode ser um fim em si mesma, não tem somente um valor relativo, isto é um preço, mas um valor intrínseco, isto é dignidade”.

6 "Essa expressão, dignidade do homem, uma vez proferida por Kant, depois se tornou a pedra de toque de todo moralista perplexo e cabeça-vazia que escondia por trás dessa imponente expressão sua falta de qualquer base moral real, ou, de qualquer forma, de vol.08, nº. 03, Rio de Janeiro, 2015.pp. 1815-1826 1818 
aduzia que todos aqueles filósofos moralistas desmiolados se escondiam atrás da expressão 'dignidade', que não trazia nenhuma base moral concreta -, Rosen se posiciona de maneira assertiva pela importância do tema no mundo contemporâneo. $\mathrm{O}$ faz, dada a relevância que a dignidade humana possui nos dias atuais, principalmente para a discussão acerca dos Direitos Humanos e também por tratar-se do conceito mais universalizável em um panorama internacionalmente aceito para a regulação normativa da vida política. (ROSEN, 2012, p. 01-02). Tal valor demonstra-se claramente pela análise de diversos documentos internacionais, tais como a Declaração Universal dos Direitos Humanos, de 1948 e as declarações regionais - América Latina, Europeia, Africana. Ademais, em diversas constituições, incluindo a brasileira, em que, em seu art. $1 .^{\circ}$, inc. III, a dignidade da pessoa humana consta como uns dos fundamentos da nação.

Entretanto, ainda que a dignidade represente um papel central no pensamento contemporâneo acerca de direitos e Direitos Humanos, ainda há, muito em decorrência da evolução histórica sobre o tema, controvérsia em relação à sua conceituação: uma das primeiras maneiras de contextualizar a dignidade historicamente, explica Rosen (2012, p. 08), é aquela em que o círculo de influência do conceito foi se alargando. A qualidade 'dignidade', anteriormente propriedade de algumas elites sociais, passou, como a ideia de direitos, a ser estendida para fora e para baixo até que pudesse ser aplicada a todos os seres humanos - isso tudo é parte desse grande, longo processo, em que a igualdade fundamental dos seres humanos veio a ser geralmente aceita. (ROSEN, 2012, p. 08, tradução nossa). ${ }^{7}$

Porém, o fato de que o conceito se expandiu de maneira a ser aceito de forma geral ainda não explica a razão de haver tantas divergências no relativo ao tema. Dignidade, historicamente, não foi somente afeta aos seres humanos, e, no século XIX, a Igreja Católica utilizou o termo como parte de um discurso anti-igualitário incisivo. (ROSEN, 2012, p. 08). Nesse passo, o autor apresenta a tese de que, como todas as noções básicas, a ideia de 'dignidade' surgiu em mais de um local e possui mais de um sentido. "Dignidade como uma característica valiosa não se restringe aos seres humanos, a dignidade como alto status social e dignidade como comportamento com um certo caráter digno de respeito (ou indignidade como comportamento que falta isso)”. (ROSEN, 2012, p. 16, tradução nossa). ${ }^{8}$

O conceito originou como um termo que denotava status e que ainda hoje é utilizado. A dignidade de mérito depende de status social ou de alguma posição formal ocupada pelo ser humano na vida. (ROSEN, 2012, p. 11). Desse modo, pode ser perdida ou adquirida. Representa um sentido clássico de dignidade, em que havia a

uma que tivesse qualquer significado. Eles astuciosamente contaram com o fato de que seus leitores estariam contentes de verem-se investidos com tal dignidade e estariam, consequentemente, bastante satisfeitos com ela”. (SCHOPENHAUER apud ROSEN, 2012, p. 01, tradução nossa).

7 "This is all part of that great, long process by which the fundamental equality of human beings has come to be generally accepted". (ROSEN, 2012, p. 08).

8 "Dignity as a valuable characteristic not restricted to human beings, dignity as high social status, and dignity as behavior with a certain respect-worthy character (or indignity as behavior lacking it)”. (ROSEN, 2012, p. 16). 
referência a algum tipo de excelência ou distinção. Comumente designava os antigos senadores da República Romana. Hoje, seria como o status do Presidente da República, alguém com muitas posses ou grande destaque em sua área.

Durante o Iluminismo (1680-1780), concebeu-se, como extensão do sentido clássico de dignidade acima indicado, a dignidade de estatura moral: resultado das ações do sujeito, sendo reconhecida àqueles seres humanos cujos pensamentos ou atitudes são revestidos de grande valor moral. Então, não é atribuída de forma equânime a toda a espécie humana. Uma pessoa, por exemplo, ao cometer o crime, deixa de possuir essa dignidade: pode-se fazer a distinção, portanto, entre a conduta dignificada e aquela que é indigna. (BROWNSWORD; BEYLEVELD, 2001, p. 58).

Entretanto, o conceito foi evoluindo com a história. Barretto (2010, p. 65) aponta que, antes mesmo de Pico della Mirandola, a questão "encontrava-se na obra de Aristóteles, Santo Agostinho, Boécio, Alcuino e Santo Tomás, indicando como através dos tempos agregaram-se valores à ideia de pessoa, que terminaram por objetivar a ideia de dignidade humana”. Rosen (2012, p. 15), porém, indica acerca da teoria do filósofo italiano renascentista Pico della Mirandola: justamente por causa do livre-arbítrio, o qual, apesar de concedido por Deus, o deixa livre para se moldar de acordo com uma ampla gama de possibilidades, que não estão disponíveis para outros animais, faz com que os indivíduos possam se realizar como pessoas, como agentes morais dotados de autonomia da vontade e arbítrio. (BARRETTO, 2010, p. 72-73). Por isso, a capacidade de escolherem seu próprio destino dá aos homens dignidade. (ROSEN, 2012, p. 15).

Nesse mesmo sentido, destaca Barretto (2010, p. 72), indicando que, justamente pela qualidade do livrearbítrio, não há limitações à natureza humana - o que acaba por ser imprescindível na diferenciação do ser humano de todos os outros animais.

A afirmação de Pico della Mirandola parece ter aberto caminho para a noção de dignidade existente hoje - dignidade como característica de todo e qualquer ser humano -, minando na época o poder dos monarcas, eis que, ao perpassar aquela ideia de dignidade de mérito, colocou todos os indivíduos no mesmo patamar de dignidade. Por isso, a dignidade da pessoa humana, também conhecida pelo termo alemão - menschenwürde ${ }^{9}$-, possui uma característica que a torna singular em relação às demais: ela não pode, sob hipótese alguma, ser mitigada. Barretto (2010, p. 68) indica como ela não é afeta a somente um indivíduo - refere-se à humanidade:

Verifica-se então como a dignidade humana encontra-se referida à questão não do indivíduo, mas da humanidade. $\mathrm{O}$ homem dos direitos humanos representa, juridicamente, o indivíduo universal no exercício de sua liberdade também universal. A humanidade, por sua vez, é a reunião

\footnotetext{
9 “A palavra alemã para a dignidade é Würde, uma palavra que está intimamente relacionada, de forma etimológica, a Wert, o termo para 'mérito' ou 'valor'. A forma adjetiva, Würdig, significa tanto 'valioso' ou 'merecedor' - como em 'merecedor de recompensa' - e 'digno'. (Há aqui um paralelo com o latim - Domine, non sum dingus - e o inglês. 'Digno', que tem, é claro, a mesma raiz que Würde, tem algo da mesma dualidade [...])". (ROSEN, 2012, p. 19, tradução nossa).
} 
simbólica de todos os homens enquanto seres humanos. Reconhece-se a pessoa como pertencente a um mesmo gênero, o 'gênero humano'.

Por isso, ela não é criada, concedida ou perdida. Já existe na pessoa, independentemente de cor, raça, credo, nacionalidade, gênero, língua, integridade física, psíquica ou moral, orientação sexual, idade ou classe social.

Rosen (2012, p. 18) coloca que, apesar de ser uma parte da história acerca da dignidade, tal noção é apenas uma parte. Trazendo a conceituação de São Tomás de Aquino ${ }^{10}$, aquela em que indica que dignidade significa a bondade de algo por si mesmo, Rosen indica que, desse ponto de vista, os seres humanos tem dignidade, mas dignidade não é algo exclusivo dos seres humanos - animais, ou até mesmo plantas, podem ter dignidade.

Se tomarmos a tradição Católica a sério, nem toda dignidade é dignidade humana. Dignidade humana é apenas uma (ainda que extremamente importante) forma de dignidade. Talvez, plantas tenham um valor intrínseco a ser também defendido. Ao menos (como o Comitê do IgNobel gostaria), é um ponto a se pensar. (ROSEN, 2012, p. 19, tradução nossa). ${ }^{11}$

Nessa próxima seção, já posta a discussão, o artigo trará diferentes abordagens para a dignidade.

\section{DIFERENTES VISÕES ACERCA DA DIGNIDADE}

Na presente seção, o texto abordará diferentes visões de dignidade, tais quais apresentadas por Michael Rosen (2012), para fazer a ligação desta com Direitos Humanos e Bioética. O artigo apresentou três diferentes escopos para o conceito de dignidade - a ideia de dignidade como status, a ideia de dignidade como valor intrínseco e a ideia de dignidade como comportamento, caráter ou atitude digna. Desse modo, Rosen coloca a questão acerca das razões pelas quais os seres humanos possuem direito aos Direitos Humanos - poucas pessoas diriam que possuem uma boa conceituação, baseada em princípios de o que são e por que tê-los. Para que uma concepção moderna de dignidade possa estar à altura de uma efetiva conceituação do termo, Rosen (2012, p. 54) indica que são necessárias três ações: primeiro, a conceituação de dignidade apresentada teria que explicar e justificar a afirmação de que todos os seres humanos compartilham essa virtude 'inviolável' e que, nela, são 'livres e iguais'. Em segundo lugar, dessa justificativa haveria de decorrer, logicamente, que os indivíduos também têm direitos invioláveis e inalienáveis. E, finalmente, seria necessário identificar quais esses direitos seriam.

Em suas conclusões, Brownsword e Beyleveld (2001, p. 13), arguindo que o discurso prático e político principal não é acerca da dignidade humana, mas sim sobre Direitos Humanos, indicam que, apesar disso, a dignidade humana inerente a todo e qualquer ser humano é a pedra basilar dos direitos inalienáveis, que são detidos por todos igualmente. Assim entendida, argumentam os autores, a dignidade humana é a rocha sobre a

\footnotetext{
10 "Dignidade significa a bondade de algo por si só”. (ROSEN, 2012, p. 17, tradição).

11 "But if we take this Catholic tradition seriously, not all dignity is human dignity. Human dignity is only one (if extremely important) form of dignity. Perhaps plants have an intrinsic value to be defended too. At least (as the Ig Nobel Committee would wish) it is a point to think about." (ROSEN, 2012, p. 19).
} 
qual a superestrutura dos Direitos Humanos está construída. A lógica dessa concepção de dignidade humana como fundamento dos Direitos Humanos, no entanto, é que o discurso prático e político principal é o dos Direitos Humanos, ao invés daquele da dignidade humana.

Cumpre salientar que a concepção usual e histórica acerca dos Direitos Humanos sempre se baseou naqueles direitos estendidos aos indivíduos, em decorrência, geralmente, das preocupações oriundas das violações à dignidade e da opressão sofrida por algum membro específico da sociedade. Nesse mesmo aspecto, as constituições e a legislação geral sempre garantiram maior espectro de proteção aos direitos individuais. Entretanto, tal concepção, muito em razão do alargamento do conceito de dignidade e da ampliação de seu escopo, não se sustenta mais: David Moeckli (2010, p. 365) coloca que os direitos humanos podem ser compreendidos em termos de necessidade de proteger a dignidade de um grupo (ou um 'povo'), e a integridade física de um grupo, bem como o seu compromisso civil, cultural, econômico, político e social. Como os direitos humanos devem refletir as realidades vividas, é necessário vê-los como mais do que apenas sobre os indivíduos. Afinal, a maioria das sociedades concede importância para as comunidades, coletivos e famílias, e o humano possui uma qualidade comum geral - a autonomia.

O direito internacional dos direitos humanos é concebido e exercido dentro do contexto das comunidades, com direitos sendo limitados (em todos, com exceção em alguns casos) pelos direitos dos outros e pelos interesses gerais da comunidade relevante. Cada indivíduo é uma parte de um ou de muitos grupos e a identidade de um indivíduo, histórias, e relacionamentos são afetados por pertencer a grupos e pelas comunidades em que vivem. (MOECKLI, 2010, p. 366, tradução nossa). ${ }^{12}$

E, justamente por causa desse alargamento do conceito de dignidade e da massificação de sua amplitude, é que se pode estabelecer outra consideração de dignidade: dignidade como respeito. Rosen (2012, p. 129) defende que respeitar a dignidade de alguém implica em tratar essa pessoa com dignidade, não a tratando com descaso, de maneira que a insulte ou a degrade - entretanto, não são apenas os vivos que merecem ser tratados com dignidade: devem-se enterrar os mortos de acordo com alguns rituais.

Nesse sentido, Rosen (2012, p. 129) ${ }^{13}$ pergunta se, para uma ação ser boa, ela deve ser em benefício de alguém. Para os utilitaristas, assumindo que a boa ação será em benefício de algum outro ser moral - o que pode incluir alguns animais -, essa resposta é afirmativa. Para essa corrente de pensamento, como se sabe, a importância reside na questão do prazer ou da dor. ${ }^{14}$ Então, se uma ação não disser respeito a um impacto em um ser moral de forma a maximizar sua utilidade, seu prazer, essa ação sai do escopo moral do utilitarismo.

\footnotetext{
12 "International human rights law is conceived and exercised within the context of communities, with rights being limited (in all except a few instances) by the rights of others and the general interests of the relevant community. Each individual is a part of one or many groups and an individual's identities, histories, and engagements are affected by belonging to groups and by the communities within which they live”. (MOECKLI, 2010, p. 366).

13 "Se uma ação é boa, ela deve ser em benefício de alguém?" (ROSEN, 2012, p. 129, tradução nossa).

${ }^{14}$ Conforme se verifica em SANDEL (2013, p. 43 e ss).
} 
Rosen (2012, p. 133), nesse mesmo sentido, coloca então uma segunda grande questão: se uma ação beneficia alguém, ela deve afetar sua consciência? Ser percebida? A questão aqui é se alguém pode se beneficiar sem que esteja se sentindo diferente - mais feliz, por exemplo. Para a resolução de tal questão, Rosen (2012, p. 134) apresenta a ideia de externalismo sobre o bem-estar. Externalismo sobre o bem-estar é uma maneira de responder à questão da razão pela qual se deve tratar os cadáveres com dignidade. Se deve tratar os cadáveres com dignidade em benefício da pessoa a quem o corpo pertencia, mesmo que ela não saiba que está melhor por ter seu cadáver tratado com dignidade, pois, óbvio, está morta. Trata-se o cadáver com dignidade por respeito a quem ele pertenceu - àquele ser moral a quem o corpo pertencia em vida.

Considerando o descrito já no começo do artigo acerca da razão kantiana pela qual o ser humano possui dignidade - a autonomia -, Rosen (2012, p. 135) pergunta sobre acerca daqueles seres não-autônomos. Um feto, por exemplo: com o exemplo do feto que não se constituiu nem se constituirá em um ser moral, a ideia de que ele deve ser tratado com respeito na hora de organizar os rituais de sepultamento não é abarcada pelo argumento externalista sobre o bem-estar. Por isso, o autor acredita que tanto o humanismo quanto o externalismo não sejam as respostas adequadas para essas questões - para Rosen (2012, p. 135) o feto, ainda assim, deve ser tratado com dignidade.

Pela alternativa, encontra-se Agostini (2009, p. 72), o qual indica que, forte na releitura da razão kantiana, em casos de perda de autonomia, a resposta para o dever do tratamento adequado é o respeito - este deve ser considerado, por aqueles que estão no pleno uso de sua autonomia, como fim em si mesmo, embora não possa dar seu consentimento. E, nesse mesmo sentido, está Barretto (2013, p. 94), que aduz: "a ação para ser moral deve ser universalizável, não negando o respeito devido a todos os indivíduos".

Em conclusão, para corroborar o transcrito acima, Rosen (2012, p. 141) explica que, para ele, como nenhuma das respostas dadas anteriormente satisfaz as questões que ele colocou, se deve tratar os outros com respeito. Por isso, mesmo que existam apenas duas pessoas no mundo e uma delas falece, a última restante deve enterrar o cadáver com dignidade, por respeito - como um dever à humanidade, mesmo que não haja mais ninguém para perceber o ato. ${ }^{15}$ Nesse mesmo sentido, indica Barretto (2010, p. 67): "a dignidade humana designaria não o ser homem, o indivíduo, mas a humanidade que se encontra em todos os seres humanos”. Ainda, para Barretto (2013, p. 94), deve-se "considerar a dignidade da pessoa humana como a categoria primordial da

\footnotetext{
${ }^{15}$ Há um interessante contraponto em Sensen (2011, p. 146 e seguintes), em especial a seção em que o autor indica que, além de não ter formado o paradigma contemporâneo de dignidade, Kant se aliava ao paradigma tradicional - dignidade como um dever a si mesmo, não à humanidade: "Kant, então, tanto sabia e aprovava o que eu chamei de paradigma tradicional da dignidade. Mas, além disso, existem passagens que indicam que ele aderiu a cada um dos quatro elementos da concepção tradicional: 1) que a dignidade refere-se a uma elevação, em vez de um valor por si só, 2) que a sua concepção de dignidade permite dois estágios: um inicial e uma concepção totalmente plena de dignidade, 3) que ele se conecta dignidade a deveres, não, em primeira instância, com direitos, e 4) que ele usa 'dignidade’ principalmente em referência a deveres para com si’. (SENSEN, 201 1, p. 165, tradução nossa). vol.08, n. 03, Rio de Janeiro, 2015.pp. 1815-1826 1823
} 
Bioética, a servir como o princípio em torno do qual se procura responder à pergunta sobre o tipo de pessoa que queremos ser e qual a sociedade que pretendemos construir".

Tomando sempre a teoria kantiana como referencial teórico, Rosen apresenta Kant como o filósofo cujo pensamento ético é governado, acima de tudo, pelo requerimento de demonstrar respeito - há o dever de agir de maneira, ao mesmo tempo, respeitosa e digna de respeito - a um núcleo de valores que cada um de nós carrega, indestrutivelmente, dentro de nós. O pensamento kantiano é da ética do dever, mas, para Rosen (2012, p. 143), pode também ser de uma ética de respeitabilidade, de honra e até de reverência.

Para Kant, o que é intrinsecamente bom deve ser tratado de uma forma que respeite o fato de sua bondade intrínseca - sua dignidade. Por 'respeito' aqui não me refiro a respeito-como-observância (que deveríamos respeitar o que é bom na maneira que nós respeitamos o limite de velocidade), mas que devemos adotar uma atitude de respeito em direção a ela e agir de maneira que seja expressiva dessa atitude. (ROSEN, 2012, p. 143, tradução nossa). ${ }^{16}$

Portanto, como se vê no excerto acima, para Rosen, com uma nítida matriz kantiana, adotar uma postura de respeito é ter sua dignidade respeitada e, ao mesmo tempo, respeitar a dignidade do outro. Nesse sentido, tal atitude encontra-se amparada também pelo imperativo categórico, dado que, se houvesse o respeito universal, a humanidade se encontraria no reino dos fins.

\section{CONSIDERAÇÕES FINAIS}

Consoante dito na introdução, o objetivo do presente artigo refere-se à possibilidade de se aclarar o conceito de dignidade, de maneira a subsidiar, pelo viés kantiano, uma discussão embasada acerca do tema propiciar correntes que indiquem as diferentes formas de abordar a dignidade. Desse modo, obedecendo a este objetivo, iniciou-se a dissertação com uma pequena introdução histórica, na qual foi apresentado o embasamento utilizado por Immanuel Kant na conceituação da dignidade, em seu paradigma contemporâneo. Demonstrou-se como o conceito de dignidade se alargou, como um círculo que se expande (ROSEN, 2012, p. 08), para abarcar diferentes formas de conceituação: dignidade como status, dignidade como uma característica não-exclusiva dos seres humanos, dignidade de comportamento (ou de estatura moral). Até finalmente chegar à conceituação contemporânea de dignidade, aquela explicitada pelo conceito alemão menschenwürde, o qual explicita que, dada a autonomia do ser humano, todos, irrestritamente, possuem dignidade.

Após, com base na doutrina de Michael Rosen, foram apresentadas diferentes abordagens para a dignidade. Ponderando acerca de importantes questões filosóficas sobre a qualidade das ações morais, o artigo

\footnotetext{
16 "For Kant, what is intrinsically good must be treated in a way that respects the fact of its intrinsic goodness - its dignity. By 'respect' here I do not mean respect-as-observance (that we should respect what is good in the way that we respect the speed limit) but that we should adopt an attitude of respect toward it and act in ways that are expressive of that attitude". (ROSEN, 2012, p. 143).
} 
apresentou duas maneiras de abordar a questão da dignidade, consoante colocadas pelo autor britânico: o externalismo sobre o bem-estar e o humanismo.

Viu-se como, apesar de suas qualidades - as quais respondem às importantes questões colocadas acima -, ambas as abordagens, entretanto, não respondem a um dos principais problemas tanto aos Direitos Humanos quanto da Bioética: qual o tipo de dever que a humanidade possui em relação a um ser não-autônomo. As implicações da resposta do autor, com fundamentação no pensamento kantiano - a ética do dever -, são inúmeras. Rosen concluiu pelo tratamento com dignidade do ser não-autônomo, justamente pela humanidade existente nos indivíduos: há que se tratar o ser não-autônomo com respeito, justamente pela bondade intrínseca do ser - pela humanidade. Pois adotar uma postura de respeito para com o outro é ver a sua própria dignidade respeitada, e também respeitar a dignidade do outro.

Nesse sentido, o tratamento do outro com respeito, mesmo que este não seja capaz de entender a atitude que lhe é dirigida, encontra-se amparado também pelo imperativo categórico, dado que, se houvesse o respeito universal, a humanidade se encontraria no reino dos fins - o agir moral, a ética do dever, a ética do respeito.

\title{
A COMPREHENSIVE APPROACH TO HUMAN DIGNITY
}

\begin{abstract}
Dignity is a concept that can encompass numerous interpretations - the term has expanded from a quality attached only by a few individuals, because of their status, to an universal, irrevocable, inalienable quality. Therefore, using the bibliographic search method, based on the doctrine of Harvard professor Michael Rosen, whose work clearly is inspired by Kantian ethics, aims to present a new facet to solve old problems, the article seeks to demonstrate, in a comprehensive manner, how the paradigm of dignity developed in history and how, today, there are difficulties in expressing it clearly. It does so in order to support further discussion on the subject and the way in which it deals with contemporary problems of Human Rights and Bioethics. Given the inner humanity in the individual, Rosen's contribution resides in the analysis of which is the best way to deal with non-autonomous beings, one of the major challenges of contemporary philosophy and science.
\end{abstract}

Keywords: Dignity. Autonomy. Liberty. Immanuel Kant. Michael Rosen.

\section{REFERÊNCIAS}

AGOSTINI, Leonardo. Autonomia: fundamento da dignidade humana em Kant. 2009. 101 f. Dissertação (Mestrado em Filosofia) - Programa de Pós-Graduação em Filosofia, Pontifícia Universidade Católica do Rio Grande do Sul, Porto Alegre, RS, 2009.

BARRETTO, Vicente de Paulo. O fetiche dos Direitos Humanos e outros temas. Porto Alegre: Livraria do Advogado, 2010. 
O fetiche dos Direitos Humanos e outros temas. 2. ed. Porto Alegre: Livraria do Advogado, 2013. BRAGATO, Fernanda Frizzo. Leituras de filosofia do direito. Curitiba: Juruá Editora, 2013.

BROWNSWORD, Roger; BEYLEVELD, Deryck. Human dignity in bioethics and biolaw. Oxford: Oxford University Press, 2001.

CHAGAS, Flávia Carvalho. O caminho crítico da Grundlegung à Crítica da Razão Prática. 2009. 182 f. Tese (Doutorado em Filosofia) -- Programa de Pós-Graduação em Filosofia, Universidade Federal do Rio Grande do Sul, Porto Alegre, RS, 2009.

CORTES, Rafael da Silva. O sumo bem e a moralidade em Kant: a função do conceito de sumo bem no processo de desenvolvimento da filosofia crítica. 2010. 138 f. Dissertação (Mestrado em Filosofia) - Programa de PósGraduação em Filosofia, Universidade Federal de Santa Maria, Santa Maria, RS, 2010.

KANT, Immanuel. Crítica da razão prática. São Paulo: Martins Fontes, 2003.

Fundamentação da metafísica dos costumes. Lisboa: Edições 70, 2007.

Fundamentação da metafísica dos costumes. São Paulo: Discurso Editorial: Barcarolla, 2009.

KATEB, George. Dignity. Cambridge: The Belknap Press of Harvard University Press, 2011.238 p.

MOECKLI, Daniel. (org) (et al.) International human rights law. New York: Oxford University Press, 2010.

ROSEN, Michael. Dignity: its history and meaning. Cambridge, Massachussetts: Harvard University Press, 2012.

SANDEL, Michael. Justiça. Rio de Janeiro: Civilização Brasileira, 2013.

SENSEN, Oliver. Kant on human dignity. Göttingen: De Gruyter, 2011.

Trabalho enviado em 02 de setembro de 2015.

Aceito em 05 de outubro de 2015. 